Check for updates

Cite this: RSC Adv., 2018, 8, 2933

Received 24th September 2017 Accepted 8th January 2018

DOI: 10.1039/c7ra10572j

rsc.li/rsc-advances

\section{Two Cu(II)-triadimenol complexes as potential fungicides: synergistic actions and DFT calculations $\dagger$}

\begin{abstract}
Jie Li, ${ }^{a}$ Huiyu Liu, ${ }^{a}$ Zhaoqi Guo, ${ }^{a}$ Mingyan Yang, ${ }^{b}$ Jirong Song ${ }^{\text {ac }}$ and Haixia Ma (D)*a
Two $\mathrm{Cu}(\mathrm{II})$ complexes, namely, $\left[\mathrm{CuL}_{4}\left(\mathrm{H}_{2} \mathrm{O}\right)_{2}\right] \cdot 2 \mathrm{NO}_{3} \cdot 2 \mathrm{CH}_{3} \mathrm{OH} 1$ and $\left[\mathrm{CuL}_{2}\left(\mathrm{CH}_{3} \mathrm{COO}\right)_{2}\right] 2$, ( $\mathrm{L}=(1 \mathrm{~S}, 2 \mathrm{R})-1-(4-$ chlorophenoxy)-3,3-dimethyl-1-(1,2,4-triazol-1-yl)butan-2-ol, triadimenol, a commercial 1,2,4-triazole pesticide) were synthesized and characterized by elemental analysis, IR spectra, UV-Vis spectra and single crystal X-ray diffraction. Crystal structural analysis shows that the different types of salts (copper acetate is covalent, while copper nitrate is ionic) contribute to different crystal structures: complex 1 consists of one copper cation, four ligands, two coordinated water molecules, two free nitrate anions and two uncoordinated methanol molecules. Complex 2 is composed of one copper cation, two ligands and two acetate anions, without free molecules. The two complexes and the ligand triadimenol were also screened for antifungal activities against four selected fungi. The antifungal results reveal that both the complexes show better bioactivities in comparison with $\mathrm{L}$, and that complex 1 has higher bioactivities than complex 2. To elaborate the reasons of the enhanced bioactivities after complexation, the interaction levels between $\mathrm{Cu}^{2+}$ cation and triadimenol, as well as the density functional theory (DFT) method were carried out. The results indicate that three factors made the antifungal activities stronger after forming $\mathrm{Cu}(॥)$ complexes: new active site of copper cation, synergic interactions between $\mathrm{Cu}^{2+}$ cation and $\mathrm{L}$, and improved penetration of the metal complexes into the lipid membranes.
\end{abstract}

\section{Introduction}

A new generation of 1,2,4-triazole fungicide is urgently needed because of its substantial environmental contamination and a rapid selection of resistant strains. ${ }^{1-6}$ Metal-based pesticides represent a novel group of fungicides with potential applications for the control of various phytopathogens. Because complexation of pesticides with metals has many advantages including the enhancement of persistence, longer shelflife, reduction of mammalian toxicity and conversion of nonsystemic to systemic pesticides. ${ }^{7-9}$ Moreover, the pesticides coordinated with transition metals could be utilized as a kind of controlled release formulation which has the capacity of alleviating the toxicity and decreasing the pesticide residue. ${ }^{\mathbf{1 0 , 1 1}}$

Triadimenol, chemically named $(1 S, 2 R)$-1-(4-chlorophenoxy)3,3-dimethyl-(1,2,4-triazol-1-yl)butan-2-ol, is an important $1 \mathrm{H}$ 1,2,4-triazole fungicide with a broad spectrum of activity against

\footnotetext{
${ }^{a}$ School of Chemical Engineering, Northwest University, Xi'an, Shaanxi 710069, China. E-mail:mahx@mwu.edu.cn; Fax: +86-029-88307755; Tel: +86-029-88307755

${ }^{b}$ Department of Environmental Science and Engineering, Chang'an University, Xi'an, Shaanxi 710054, China

${ }^{c}$ Conservation Technology Department, The Palace Museum, Beijing, China

$\dagger$ Electronic supplementary information (ESI) available. CCDC 14142571 and 1055002 2. For ESI and crystallographic data in CIF or other electronic format see DOI: $10.1039 / \mathrm{c} 7 \mathrm{ra} 10572 \mathrm{j}$
}

mildews and rusts in cereals, fruits and vegetables. ${ }^{12,13}$ This compound inhibits fungal proliferation by the interference with steroid biosynthesis and fungal cell-membrane formation mediated by cytochrome P450-dependent $14 \alpha$-sterol demethylase (P450DM), an essential enzyme in ergosterol biosynthesis in fungi and cholesterol synthesis in mammalian cells. ${ }^{\mathbf{1 4}}$ However, the intensive use and single active site of triadimenol have led to the problem of the antifungal resistance. ${ }^{15-17}$

Although the complexes of triadimenol have many potential advantages and synthetic accessibility, the related research is still rare. ${ }^{18-20}$ Zhang reported the synthesis and crystal structure of $\mathrm{CuCl}_{2}$ complex with triadimenol. ${ }^{18}$ Qian reported the formation, crystal structure and dielectric physical properties of its $\mathrm{Cu}\left(\mathrm{CH}_{3} \mathrm{COO}\right)_{2}$ complex with triadimenol. ${ }^{19}$ Our group reported the structure, crystal structure and antifungal activities of $\mathrm{ZnBr}_{2}$ complex with triadimenol and found that the $\mathrm{Zn}$ (II) complex are more active than triadimenol against Botryosphaeria ribis, Gibberella nicotiancola, Colletotrichum gloeosporioides and Alternaria solani. ${ }^{20}$ To inject new vitality into triadimenol, we are interested in exploiting the $\mathrm{Cu}(\mathrm{II})$ coordination chemistry of triadimenol and the potential application in agricultural application. Even though the structure of the complex of triadimenol and copper acetate $\left[\mathrm{CuL}_{2}\left(\mathrm{CH}_{3} \mathrm{COO}\right)_{2}\right] 2$ ( $\mathbf{L}=$ triadimenol) has been proposed, ${ }^{19}$ its antifungal activities against the selected phytopathogens such as Elsinoe ampelina, Glomerella cingulata, Physalospora berengeriana and Gibberella 
saubinetii and its theoretical investigation of the electronic structure have not yet been reported, to the best of our knowledge.

In this paper, two $\mathrm{Cu}$ (II) complexes based on triadimenol $\mathbf{L}$, $\left[\mathrm{CuL}_{4}\left(\mathrm{H}_{2} \mathrm{O}\right)_{2}\right] \cdot 2 \mathrm{NO}_{3} \cdot 2 \mathrm{CH}_{3} \mathrm{OH} 1$ and $\left[\mathrm{CuL}_{2}\left(\mathrm{CH}_{3} \mathrm{COO}\right)_{2}\right] 2$ were prepared. Their crystal structures and antifungal activities against four selected plant pathogenic fungi were also reported. Additionally, with the assistance of density functional theoretical (DFT) investigation, a reason analysis of the increased bioactivities was made in this paper.

\section{Results and discussion}

\subsection{Synthesis, IR, UV-Vis, EPR spectroscopy and magnetic properties}

As shown in Scheme 1, reaction of triadimenol with $\mathrm{Cu}\left(\mathrm{NO}_{3}\right)_{2}$ $\cdot 3 \mathrm{H}_{2} \mathrm{O}$ led to a mononuclear triazole complex coordinated with four ligands and two water molecules. The nitrate anions did not participate with coordination. While, reaction of triadimefon with the dimer of $\mathrm{Cu}\left(\mathrm{CH}_{3} \mathrm{COO}\right)_{2} \cdot \mathrm{H}_{2} \mathrm{O}$ generated a mononuclear complex coordinated with only two ligands and two acetate anions.

Both complexes 1 and 2 display the characteristic bands of hydroxyl groups. The hydroxyl $\nu(\mathrm{O}-\mathrm{H})$ stretching vibrations in the IR spectrum of 1 and 2 are present at 3362 and $3340 \mathrm{~cm}^{-1}$, respectively. The bands observed in $3137-2867 \mathrm{~cm}^{-1}$ region are assigned to the stretching $\mathrm{C}-\mathrm{H}$ vibrations of complexes $\mathbf{1}$ and $\mathbf{2}$. The IR absorption band at $1386 \mathrm{~cm}^{-1}$ of complex 1 may correspond to the antisymmetric stretching vibration $\nu(\mathrm{NO})$ of nitrate. This suggest the nitrate group is in uncoordinated manner. In complex 2 , the absorption bands at $1403 \mathrm{~cm}^{-1}$ and $1578 \mathrm{~cm}^{-1}$ are attributed to $\nu_{\mathrm{s}}\left(\mathrm{COO}^{-}\right)$and $\nu_{\text {as }}\left(\mathrm{COO}^{-}\right)$, respectively, which indicates that the coordinated behavior of the acetato group with the central metal ion in bidentate manner. ${ }^{21}$

The UV-Vis spectra of the complexes $\mathbf{1}$ and $\mathbf{2}$ and the ligand $\mathbf{L}$ were recorded in $\mathrm{CH}_{3} \mathrm{OH}$ (Fig. $\mathrm{S} 1 \dagger$ ). For $\mathbf{L}$, the absorption bands at 222, $276 \mathrm{~nm}$ are attributed to $\pi-\pi^{*}$ and $\mathrm{n}-\pi^{*}$ transitions. Upon complexation, the $\pi-\pi^{*}$ band shifts from 224 and $223 \mathrm{~nm}$, while the $\mathrm{n}-\pi^{*}$ band moves to $275 \mathrm{~nm}$. Furthermore both the complexes present a relatively broad band in the visible region, with maxima centered at about $535 \mathrm{~nm}$ and $528 \mathrm{~nm}$, respectively for complex 1 and 2 , indicating a distorted octahedral geometry in each case. The broadness of the band observed in each case may be attributed to Jahn-Teller distortions. ${ }^{22}$ In $\mathrm{Cu}(\mathrm{II})$ octahedral or pseudo-octahedral environments this band is usually composed of a number of components that in all the present cases remain unresolved. These bands

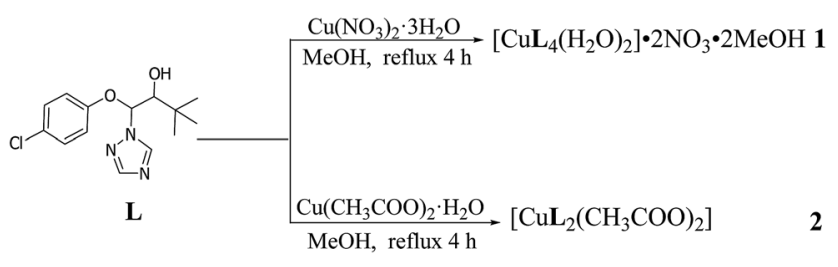

Scheme 1 Formation of the complexes with triadimenol. originated in transitions from the $\mathrm{d}_{x y}, \mathrm{~d}_{z}{ }^{2}$ and $\mathrm{d}_{x z}, \mathrm{~d}_{y z}$ pair to the $\sigma$ antibonding and half-filled $\mathrm{d}_{x^{2}}-\mathrm{d}_{y^{2}}$ level and the relative order of these transitions depend upon the extent of axial metal-ligand interaction and on the overall geometry around the metal center, which indicates that there is electron transfer between metal ions and the ligand. ${ }^{23}$

The EPR spectra of the two $\mathrm{Cu}(\mathrm{II})$ complexes were recorded at room temperature as crystal sample (Fig. S2 $\dagger$ ). They exhibit a well-resolved anisotropic signal in the parallel and perpendicular $\mathrm{Cu}^{2+}$ region. There are three hyperfine peaks in the parallel region derived from the coupling of the copper nucleus and the unpaired electron. The observed data show that $g_{\|}=$ 2.226 for complex 1 and 2.223 for complex 2, and the data of $g_{\perp}$ for complex 1 and complex 2 are 2.054 and 2.048, respectively. The results indicate the oxidation state of copper in both the complexes to be +2 . The fact $g_{\|}>g_{\perp}$ confirms an elongated octahedral stereochemistry with $\mathrm{a} \mathrm{d}_{x^{2}}-\mathrm{d}_{y^{2}}$ ground state in both the complexes, ${ }^{24}$ which is in good agreement with the determined X-ray structures.

The $X_{\mathrm{M}} T$ versus $T$ plot $\left(X_{\mathrm{M}} T\right.$ being the magnetic susceptibility per $\mathrm{Cu}$ atom) of the two complexes is given in Fig. S3. $\dagger$ At room temperature the $X_{\mathrm{M}} T$ values for complexes 1 and 2 are 0.38 and $0.39 \mathrm{~cm}^{3} \mathrm{~mol}^{-1} \mathrm{~K}$, respectively, which agrees well with that expected for isolated copper(II) ions, ${ }^{25}$ clearly demonstrating both the two $\mathrm{Cu}$ (II) complexes are mononuclear complexes. The $X_{\mathrm{M}} T$ of the two complexes remains almost constant until around $50 \mathrm{~K}$ and then sharply decreases to a value $0.35-0.36 \mathrm{~cm}^{3} \mathrm{~mol}^{-1} \mathrm{~K}$ at $2 \mathrm{~K}$. This decrease is due to very weak intermolecular antiferromagnetic interactions. ${ }^{26}$

\subsection{Molecular structures of complexes 1 and 2}

As shown in Fig. 1a and 2a, although both the $\mathrm{Cu}$ (II) centers in the two title complexes absorb octahedral geometry, the coordination environments of the $\mathrm{Cu}$ (II) centers in the two complexes are different. In complex $\mathbf{1}$, the $\mathrm{Cu}(\mathrm{II})$ atom is coordinated with four $\mathbf{L}$ ligands and two water molecules. While two $\mathrm{NO}_{3}{ }^{-}$anions and two methanol molecules are present in the 2nd coordination sphere (Fig. 1a). However, in complex 2, the $\mathrm{Cu}$ (II) atom is coordinated with only two $\mathbf{L}$ ligands and two $\mathrm{CH}_{3} \mathrm{COO}^{-}$anions without free molecules (Fig. 2a). The different types of salts (copper acetate is covalent, while copper nitrate is ionic) should be due to the diversified crystal structures even with the same ligand and metal centers.

In complex $1, \mathrm{Cu}$ atom and four coordinated $\mathrm{N}$ atoms from four triazole rings form the equatorial plane. The least-squares plane equation is $7.635 x+2.877 y+3.759 z=9.0731$, with the mean deviation from the plane $0 \AA$, indicating that these five atoms form a perfect plane. The axial position is occupied by $\mathrm{Cu}, \mathrm{O} 9 \mathrm{w}$ and $\mathrm{O} 9 \mathrm{w}^{\mathrm{i}}$ atoms. The $\mathrm{Cu}-\mathrm{O} 9 \mathrm{w}$ bond length is 2.392(2) $\AA$, much longer than the $\mathrm{Cu}-\mathrm{N}$ bond lengths (2.035(2) and 2.153(2) A), thus forming an elongated octahedron around the $\mathrm{Cu}$ atom. The dihedral angles of benzene ring planes and their attached triazole planes are $75.709(109)^{\circ}$ and $75.632(87)^{\circ}$, respectively. The triazole ring planes are coplanar with their symmetric planes, and approximately perpendicular to their adjacent triazole ring planes (dihedral angle $77.802(98)^{\circ}$ ). While 


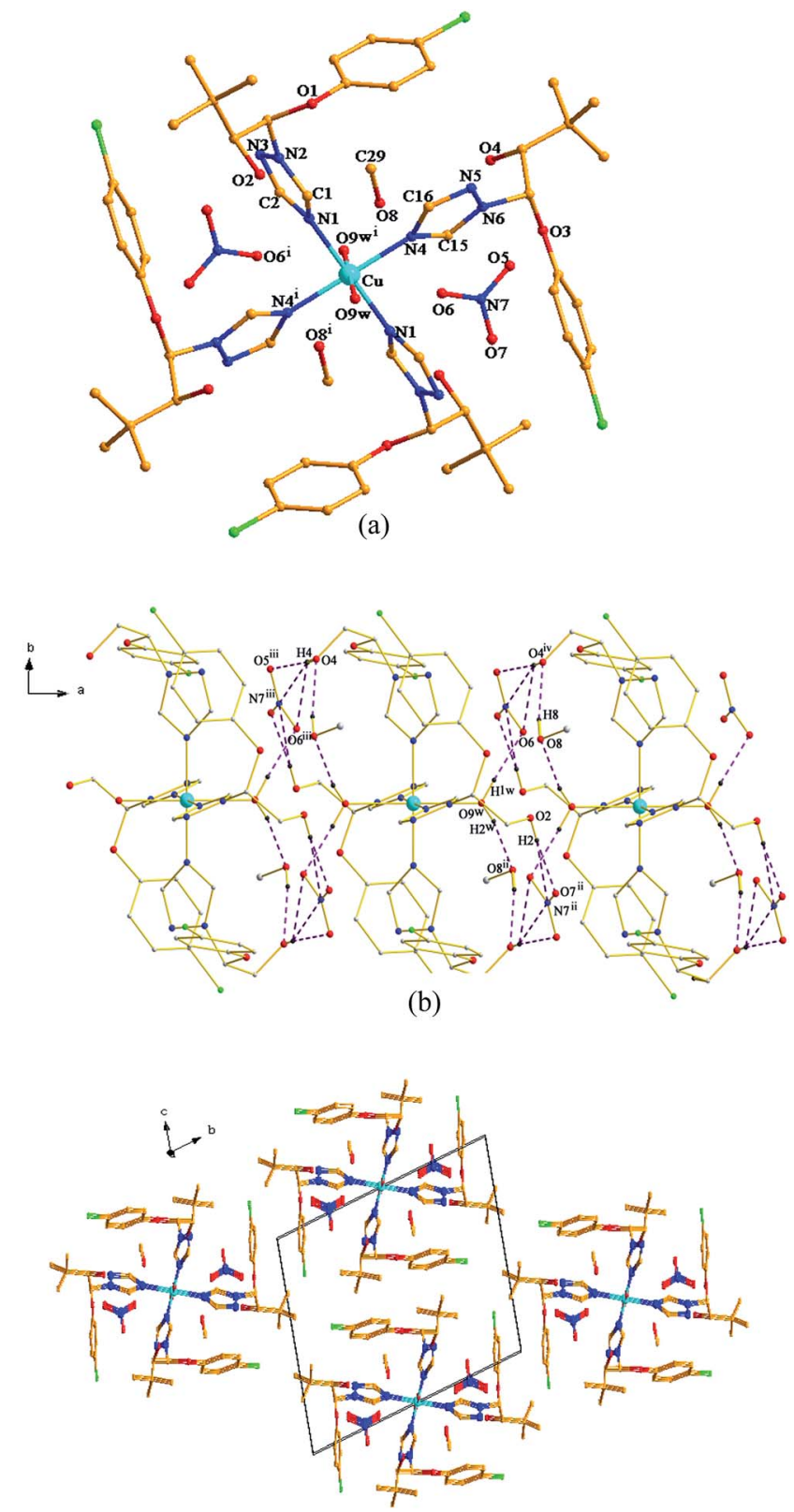

(c)

Fig. 1 Crystal structures of complex 1 (a) coordination mode (symmetry code: (i) $-x+2,-y+1,-z$ ), hydrogen atoms are omitted for clarity. (b) 1D chain formed via hydrogen bonds. Terminal butyl groups of the ligands are omitted for clarity (symmetry code: (ii) $-x+1$, $-y+1,-z$; (iii) $x+1, y, z$; (iv) $x-1, y, z$ ). (c) Crystal packing along the a-axis.

in complex 2, $\mathrm{Cu}$ atom and four $\mathrm{O}$ atoms from two $\mathrm{CH}_{3} \mathrm{COO}^{-}$ anions define the equatorial plane, and the least-squares plane equation is $3.315 x+5.963 y+2.834 z=10.5179$, with the mean deviation from the plane $0 \AA$. The axial position is occupied by $\mathrm{Cu}, \mathrm{N} 1$ and $\mathrm{N}^{\mathrm{i}}$ atoms. The $\mathrm{Cu}-\mathrm{N}$ bond length is $1.9950(18) \AA$, which is slightly shorter than that of complex 1 . The bond length of $\mathrm{Cu}-\mathrm{O} 1$ is $2.6610(27) \AA$, much longer than that of $\mathrm{Cu}-$ O2 (1.9410(16) A). The triazole ring plane is coplanar with its symmetric plane. The dihedral angle of benzene ring planes
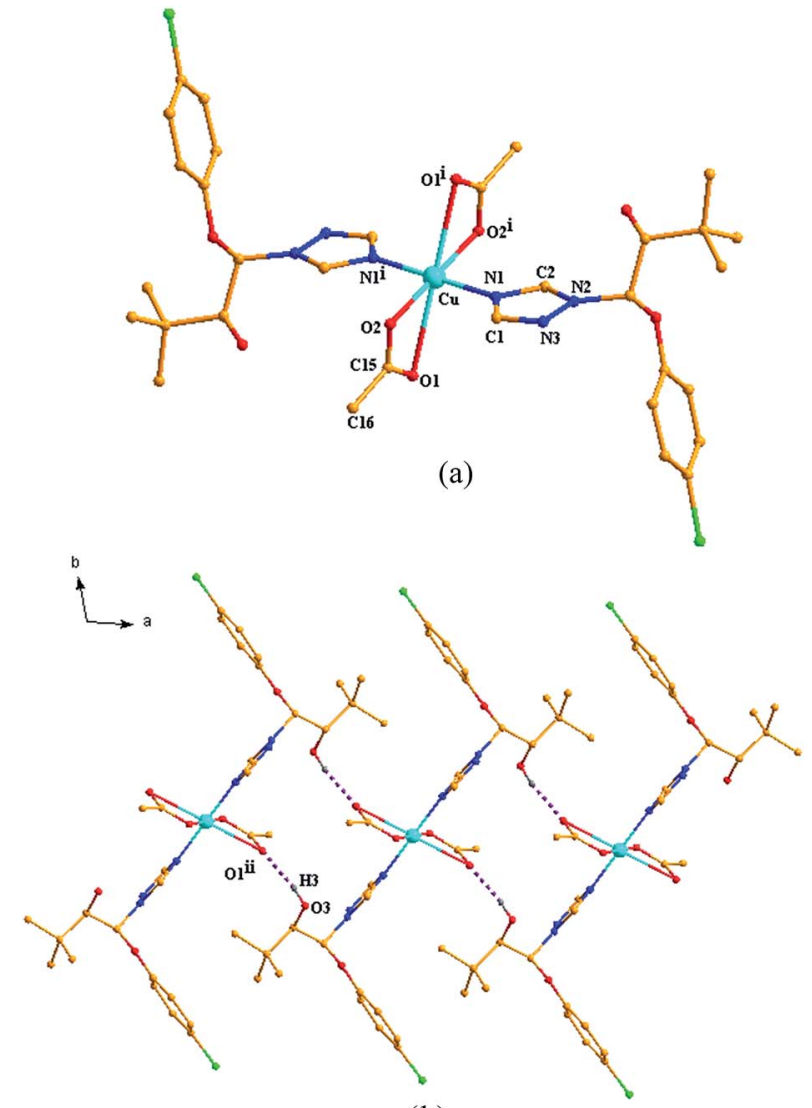

(b)

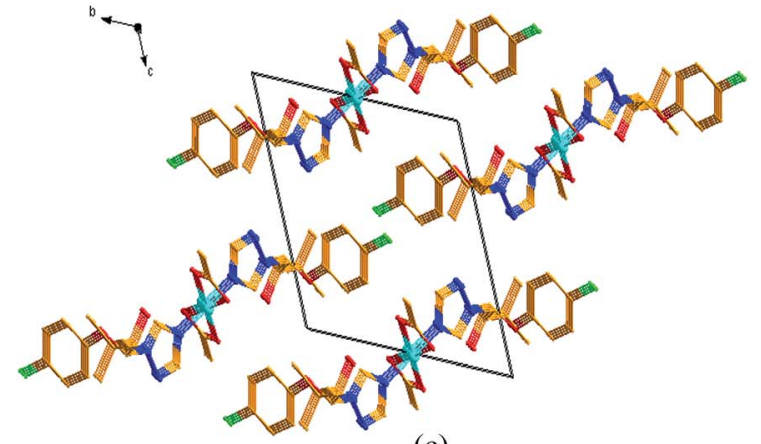

(c)

Fig. 2 Crystal structures of complex 2 (a) coordination mode (symmetry code: (i) $-x+1,-y+1,-z+2$ ), hydrogen atoms are omitted for clarity. (b) 1D chain formed via hydrogen bonds (symmetry code: (ii) $-x+2,-y+1,-z+2$ ). (c) Crystal packing along the a-axis.

and their attached triazole planes is $77.433(81)^{\circ}$, which is close to those of complex $\mathbf{1}$.

Both of the two complexes form infinite chain structures by hydrogen bonds. As shown in Fig. 1b, in the structure of complex 1, there is one kind of intramolecular hydrogen bond O9w-H1w $\cdots$ O6, which is generated by O9w atom of water molecule as hydrogen bond donor to $\mathrm{O} 6$ of free nitrate. And there are seven kinds of intermolecular hydrogen bonds: $\mathrm{O} 2$ atom takes part in hydrogen bonds of $\mathrm{O} 2-\mathrm{H} 2 \cdots \mathrm{O} 7^{\mathrm{ii}}, \mathrm{O} 2-\mathrm{H} 2 \cdots$ $\mathrm{N} 7{ }^{\mathrm{ii}}$ and $\mathrm{O} 9 \mathrm{w}$ also takes part in hydrogen bond of $\mathrm{O} 9-\mathrm{H} 2 \mathrm{w} \cdots \mathrm{O} 8^{\mathrm{ii}}$ (symmetry code: (ii) $-x+1,-y+1,-z$ ); $\mathrm{O} 4$ atom acts as 
hydrogen bond donor to $\mathrm{O}^{\mathrm{iii}}$, $\mathrm{O}^{\mathrm{iii}}$ and $\mathrm{N}^{\mathrm{iii}}$ of free nitrate forming hydrogen bonds of $\mathrm{O} 4-\mathrm{H} 4 \cdots \mathrm{O} 5^{\mathrm{iii}}, \mathrm{O} 4-\mathrm{H} 4 \cdots \mathrm{O} 6^{\mathrm{iii}}$ and $\mathrm{O} 4-\mathrm{H} 4 \cdots \cdots \mathrm{N}^{\mathrm{iii}}$ (symmetry code: (iii) $x+1, y, z$ ); meanwhile, $\mathrm{O} 4$ atom also acts as hydrogen bond acceptor to $\mathrm{O} 8$ from the adjacent molecule, generating $\mathrm{O} 8-\mathrm{H} 8 \cdots \mathrm{H} 4^{\mathrm{iv}}$ (symmetry code: (iv) $x-1, y, z$ ). The intermolecular hydrogen bonds contribute to the formation of a one-dimensional framework along $c$-axis in the crystal structure of complex 1 (Fig. 1b). In the structure of complex 2, there is only one kind of intermolecular hydrogen bond: the hydroxyl groups of the ligand form hydrogen bond with the coordinated $\mathrm{O} 1$ atom from $\mathrm{CH}_{3} \mathrm{COO}^{-}$anion on the adjacent $\left[\mathrm{CuL}_{2}\left(\mathrm{CH}_{3} \mathrm{COO}\right)_{2}\right]$ units of $\mathrm{O} 3-\mathrm{H} 3 \cdots \mathrm{O}^{\mathrm{ii}}\left(\mathrm{H}_{3} \cdots \mathrm{O}^{\mathrm{ii}}\right.$ $1.916 \AA$ ), thus generating a 1D chain along $c$-axis (Fig. 2b). As illustrated in Fig. 1c and 2c, the 1D chains are connected by van der Waals forces to give the 3D framework along the $a$-axis in both the two complexes.

Structure refinement details of the complexes are summarized in Table 1. Selected bond lengths and angles are listed in Table 2, and hydrogen bonds are shown in Table 3.

\subsection{Biological activities}

2.3.1 Antifungal activities. It can be seen from Table 4 that the synthesized metal complexes show higher antifungal activities than the ligand $\mathbf{L}$ against the four selected fungi, and the antifungal activity is ranked as complex $\mathbf{1}>$ complex $\mathbf{2}>\mathbf{L}$. Moreover, complex $\mathbf{1}$ has stronger antifungal activities than the reported $\mathrm{Cu}$ complexes based on triadimefon against $G$. cingulate and P. berengeriana. ${ }^{27}$ From Table 4, we can also observe that the antifungal toxicities of complex 1 are 3.78-6.90 times greater than those of $\mathbf{L}$, while the toxicities of complex $\mathbf{2}$ were 1.79-4.40 times higher than those of $\mathbf{L}$. Overall, the toxicities of complex 1 is 1.57-2.84 times better than those of complex 2 .

The bioassay of the metal salts (Fig. 3) show that $\mathrm{Cu}\left(\mathrm{NO}_{3}\right)_{2}$ and $\mathrm{Cu}\left(\mathrm{CH}_{3} \mathrm{COO}\right)_{2} \cdot \mathrm{H}_{2} \mathrm{O}$ have certain inhibitory effects on the

Table 1 Crystallographic data for 1 and 2

\begin{tabular}{lll}
\hline Parameter & $\mathbf{1}$ & $\mathbf{2}$ \\
\hline Empirical formula & $\mathrm{C}_{58} \mathrm{H}_{84} \mathrm{Cl}_{4} \mathrm{CuN}_{14} \mathrm{O}_{18}$ & $\mathrm{C}_{32} \mathrm{H}_{42} \mathrm{Cl}_{2} \mathrm{CuN}_{6} \mathrm{O}_{8}$ \\
Formula weight & 1470.73 & 773.15 \\
Cryst system & Triclinic & Triclinic \\
Space group & $P \overline{1}$ & $P \overline{1}$ \\
$a(\AA)$ & $7.8341(16)$ & $8.5849(16)$ \\
$b(\AA)$ & $15.510(3)$ & $10.5243(19)$ \\
$c(\AA)$ & $16.076(3)$ & $12.043(3)$ \\
$\alpha\left({ }^{\circ}\right)$ & $68.996(4)$ & $111.668(4)$ \\
$\beta\left({ }^{\circ}\right)$ & $88.380(4)$ & $108.999(4)$ \\
$\gamma\left({ }^{\circ}\right)$ & $88.253(4)$ & $96.088(3)$ \\
$V\left(\AA^{3}\right)$ & $1822.4(6)$ & $923.9(3)$ \\
$Z$ & 1 & 1 \\
$D_{\mathrm{c}}(\mathrm{g}$ cm & -3 \\
$F(000)$ & 1.340 & 1.390 \\
Reflcns collcd & 771 & 403 \\
Unique/observed & 8863 & 4768 \\
$R_{\text {int }}$ & $6315 / 4408$ & $3399 / 3022$ \\
Goodness-of-fit on $F^{2}$ & 0.0265 & 0.0184 \\
$R_{1}(I \geq 2 \sigma(I))$ & 0.999 & 1.140 \\
w $R_{2}(I \geq 2 \sigma(I))$ & 0.0512 & 0.0387 \\
& 0.1276 & 0.1177
\end{tabular}

Table 2 Selected bond lengths $(\AA)$ and angles $\left({ }^{\circ}\right)$ for complex 1 and $2^{a}$

\begin{tabular}{llll}
\hline Complex 1 & \multicolumn{3}{c}{ Complex 2} \\
\hline $\mathrm{Cu}-\mathrm{N} 1$ & $2.035(2)$ & $\mathrm{Cu}-\mathrm{N} 1$ & $1.9950(18)$ \\
$\mathrm{Cu}-\mathrm{N} 1^{\mathrm{i}}$ & $2.035(2)$ & $\mathrm{Cu}-\mathrm{N} 1^{\mathrm{i}}$ & $1.9950(18)$ \\
$\mathrm{Cu}-\mathrm{N} 4$ & $2.030(2)$ & $\mathrm{Cu}-\mathrm{O} 1$ & $2.6610(27)$ \\
$\mathrm{Cu}-\mathrm{N} 4^{\mathrm{i}}$ & $2.030(2)$ & $\mathrm{Cu}-\mathrm{O} 1^{\mathrm{i}}$ & $2.6610(27)$ \\
$\mathrm{Cu}-\mathrm{O} 9 \mathrm{w}$ & $2.392(2)$ & $\mathrm{Cu}-\mathrm{O} 2$ & $1.9410(16)$ \\
$\mathrm{Cu}-\mathrm{O} 9 \mathrm{w}^{\mathrm{i}}$ & $2.392(2)$ & $\mathrm{Cu}-\mathrm{O} 2^{\mathrm{i}}$ & $1.9410(16)$ \\
$\mathrm{N} 1-\mathrm{Cu}-\mathrm{N} 1^{\mathrm{i}}$ & $180.00(13)$ & $\mathrm{N} 1-\mathrm{Cu}-\mathrm{N} 1^{\mathrm{i}}$ & $180.00(12)$ \\
$\mathrm{N} 4-\mathrm{Cu}-\mathrm{N} 4^{\mathrm{i}}$ & $180.00(18)$ & $\mathrm{O} 2-\mathrm{Cu}-\mathrm{O} 2^{\mathrm{i}}$ & $180.00(13)$ \\
$\mathrm{O} 9 \mathrm{w}-\mathrm{Cu}-\mathrm{O} 9 \mathrm{w}^{\mathrm{i}}$ & $180.00(11)$ & $\mathrm{O} 1-\mathrm{Cu}-\mathrm{O} 1^{\mathrm{i}}$ & $180.00(1)$ \\
$\mathrm{N} 1-\mathrm{Cu}-\mathrm{N} 4$ & $91.01(9)$ & $\mathrm{N} 1-\mathrm{Cu}-\mathrm{O} 2$ & $89.13(7)$ \\
$\mathrm{N} 1-\mathrm{Cu}-\mathrm{N} 4^{\mathrm{i}}$ & $88.99(9)$ & $\mathrm{N} 1-\mathrm{Cu}-\mathrm{O} 2^{\mathrm{i}}$ & $90.87(7)$
\end{tabular}

${ }^{a}$ Symmetry codes: complex 1 (i) $-x+2,-y+1,-z$. Complex 2 (i) $-x+1$, $-y+1,-z+2$.

Table 3 Hydrogen bonds for complex 1 and $2^{a}$

\begin{tabular}{|c|c|c|c|c|}
\hline $\mathrm{D}-\mathrm{H} \cdots \mathrm{A}$ & $\mathrm{D}-\mathrm{H}$ & $\mathrm{H} \cdots \mathrm{A}$ & $\mathrm{D} \cdots \mathrm{A}$ & $\angle \mathrm{D}-\mathrm{H} \cdots \mathrm{A}$ \\
\hline \multicolumn{5}{|l|}{ Complex 1} \\
\hline $\mathrm{O} 9 \mathrm{w}-\mathrm{H} 1 \cdots \mathrm{O} 6$ & 0.844 & 2.039 & 2.845 & 159.65 \\
\hline $\mathrm{O} 2-\mathrm{H} 2 \cdots \mathrm{O} 7^{\mathrm{ii}}$ & 0.820 & 1.949 & 2.753 & 166.36 \\
\hline $\mathrm{O} 2-\mathrm{H} 2 \cdots \mathrm{N} 7^{\mathrm{ii}}$ & 0.820 & 2.689 & 3.491 & 166.23 \\
\hline $\mathrm{O} 9 \mathrm{w}-\mathrm{H} 2 \cdots \mathrm{O} 8^{\mathrm{iii}}$ & 0.843 & 1.964 & 2.796 & 169.03 \\
\hline $\mathrm{O} 4-\mathrm{H} 4 \cdots \mathrm{O} 5^{\mathrm{iii}}$ & 0.820 & 2.009 & 2.808 & 164.36 \\
\hline $\mathrm{O} 4-\mathrm{H} 4 \cdots \mathrm{O}^{\mathrm{iii}}$ & 0.820 & 2.545 & 3.098 & 125.94 \\
\hline $\mathrm{O} 4-\mathrm{H} 4 \cdots \mathrm{N} 7^{\mathrm{iii}}$ & 0.820 & 2.584 & 3.338 & 153.52 \\
\hline $\mathrm{O} 8-\mathrm{H} 8 \cdots \mathrm{O} 4^{\mathrm{iv}}$ & 0.820 & 1.977 & 2.754 & 157.88 \\
\hline \multicolumn{5}{|l|}{ Complex 2} \\
\hline $\mathrm{O} 3-\mathrm{H} 3 \cdots \mathrm{O} 1^{\mathrm{ii}}$ & 0.820 & 1.977 & 2.754 & 157.88 \\
\hline
\end{tabular}

Table $4 \quad E_{50}\left(\mathrm{mg} \mathrm{L}^{-1}\right)$ values for $\mathrm{L}$ and the metal complexes tested against plant pathogenic fungi

\begin{tabular}{lllll}
\hline Compound & E. ampelina & G. cingulata & P. berengeriana & G. saubinetii \\
\hline $\mathbf{1}$ & 1.81 & 1.46 & 1.20 & 0.97 \\
$\mathbf{2}$ & 3.34 & 4.15 & 2.53 & 1.52 \\
$\mathbf{L}$ & 8.39 & 7.63 & 4.54 & 6.69 \\
\hline
\end{tabular}

four plant pathogenic fungi and the inhibition rate increases with the growth of the concentration of the metal salts. It also can be found that the fungicidal activities of $\mathrm{Cu}\left(\mathrm{NO}_{3}\right)_{2}$ and $\mathrm{Cu}\left(\mathrm{CH}_{3} \mathrm{COO}\right)_{2} \cdot \mathrm{H}_{2} \mathrm{O}$ against the same selected fungi did not exhibit obvious diversity; this result indicates that the bioactivities of the title complexes were related to only the ligand and metal cation, substantively irrelative to the anions. Therefore, it was the coordination of the ligand and the $\mathrm{Cu}$ cation that increased the bioactivities.

2.3.2 Synergistic interaction between copper cations and triadimenol. Fig. 4 gives information of the interactions between the copper cations and triadimenol in both the complexes. It can be obtained from Fig. 4: (i) all the interaction levels between $\mathrm{Cu}$ cation and triadimenol were synergistic 

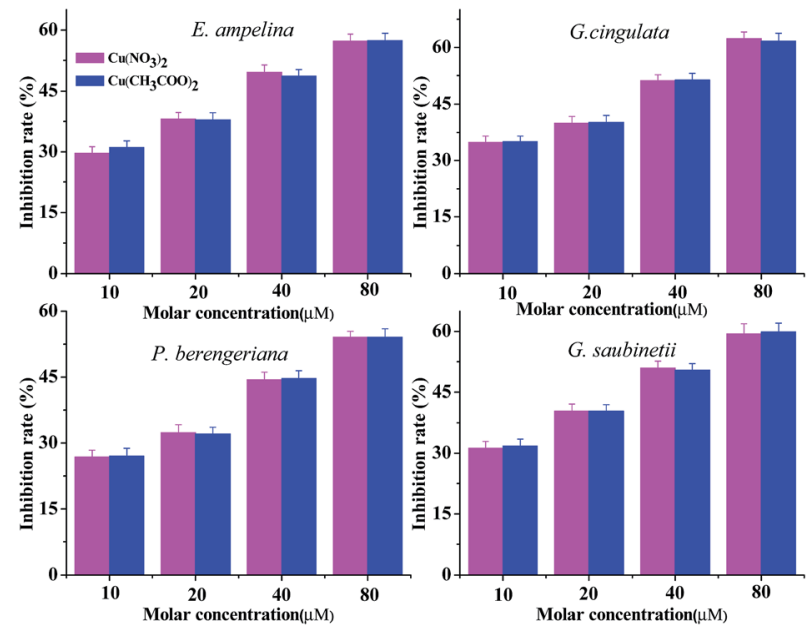

Fig. 3 / inhibiting rates (\%) of copper salts with various concentrations.

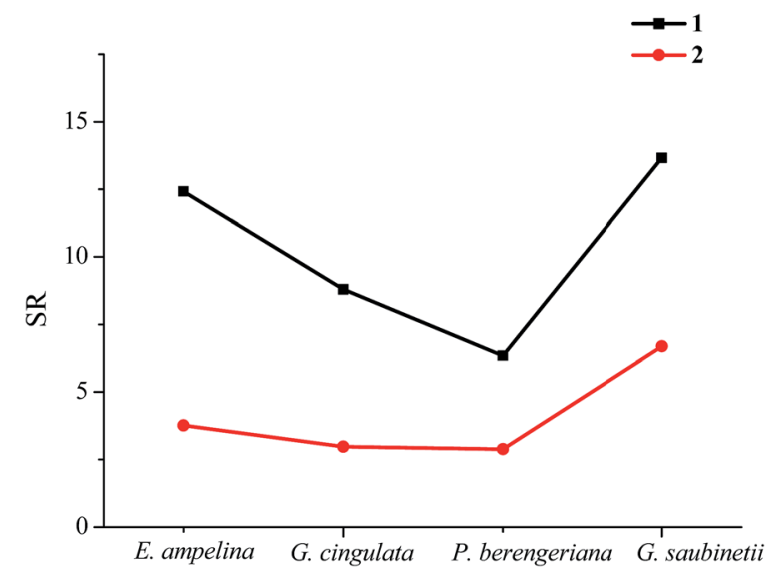

Fig. 4 Interaction (SR) between copper cations and tebuconazole.

against the four selected fungi, since all the values of SR are more than 1.5 (the minimum SR is 2.87). ${ }^{28}$ The result should be one reason for the enhanced bioactivities after complexation; (ii) the interaction levels of complex $\mathbf{1}$ were higher than those of complex $\mathbf{2}$ for the same tested fungus, which indicates that the synergy levels are strongly dependent on the ratio of the components in the mixture, and here the synergy levels were better for the ratio $1: 4$ of the molecular-level mixture of copper cation and triadimenol than that for the ratio $1: 2$. This also leads to higher bioactivities for complex 1 than complex 2 against the selected fungi; (iii) both the synthesized complexes show different synergy levels to the different tested fungi. The synergy levels concerning the tested fungi are in the sequence of G. saubinetii $>$ E. ampelina $>$ G. cingulata $>P$. berengeriana, which implies that the antifungal activities against $G$. saubinetii are improved to the greatest extent, and against $P$. berengeriana to the smallest extent after complexation.

\subsection{Theoretical calculations}

2.4.1 Geometry optimization. Full geometry optimization of the complexes $\mathbf{1}$ and $\mathbf{2}$ was constructed based on their crystallographic data using density functional theory. The accuracy of the geometry optimization was verified by wavenumber calculations. Positive values of all the calculated vibrational wave numbers confirmed the geometries of complexes $\mathbf{1}$ and $\mathbf{2}$ to be located on the true local minima on the potential energy surface. To make the comparison easy, the calculated geometric parameters of the complexes $\mathbf{1}$ and $\mathbf{2}$ are also listed in Table S1. $\dagger$ Comparing the theoretical values with the experimental ones, all of the optimized bond lengths and angles are slightly larger than the experimental values. This overestimation can be explained that the theoretical calculations belong to isolated molecule in gaseous phase and the experimental results belong to similar molecule in solid state. ${ }^{29}$

2.4.2 HOMO-LUMO analysis. The frontier orbitals, highest occupied molecular orbital (HOMO) and lowest unoccupied molecular orbital (LUMO), can be used to describe electron donors and electron acceptors, which influence the bioactivity and determine the way a molecule interacts with the biological species. $^{30,31}$ The study on their frontier orbitals can provide useful information for the working mechanism of the bioactive compounds, ${ }^{32,33}$ such as active sites. The plots of HOMO, LUMO of complexes $\mathbf{1}$ and $\mathbf{2}$ are shown in Fig. 5. The modes in each HOMO and LUMO are symmetrically placed as illustrated in Fig. 5. The HOMO and LUMO of complex 1 are localized predominantly on $\mathrm{Cu}$ cation and four coordinated triazole rings. The HOMO and LUMO of complex 2 are localized predominantly on copper cation, two coordinated triazole rings and two $\mathrm{CH}_{3} \mathrm{COO}^{-}$anions. The fact that metal ions make a contribution to FMO orbitals in both the complexes is in good agreement with the result of UV-Vis spectra that there is electron transfer between metal ions and the ligand. The HOMOLUMO results imply that the metal cations, the coordinated anions and triazole rings may be the reactive sites of the two complexes.

2.4.3 Mulliken charges analysis. The atomic charge populations of a molecule is closely related to active site in its electrophilic or nucleophilic reactions and the charge interaction between two molecules. ${ }^{34}$ These interactions can play

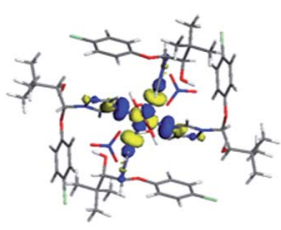

(a)

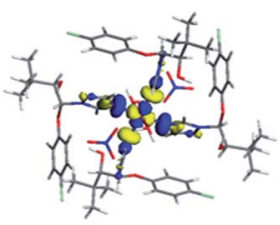

(b)

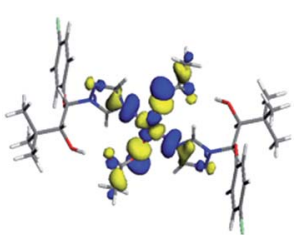

(c)

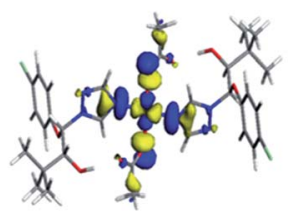

(d)
Fig. $5 \mathrm{HOMO}$ and LUMO plots of complexes 1 and 2. (a) HOMO of complex 1. (b) LUMO of complex 1. (c) HOMO of complex 2. (d) LUMO of complex 2 . 
crucial role in inhibiting the growth of fungi. ${ }^{35}$ The Mulliken atomic charges of complexes 1, 2 and $\mathbf{L}$ obtained by means of Mulliken population analysis, are tabulated in Table 5. It is clear that the coordination leads to the redistribution of electron density, especially in the triazole ring moieties coordinated with $\mathrm{Cu}(\mathrm{II})$ cation. The transferred charges decrease polarization. ${ }^{36}$ The center $\mathrm{Cu}^{2+}$ gain electrons to exhibit positive charges of $0.613 e$ for complex 1 and $0.618 e$ for complex 2 . While the anions $\mathrm{NO}_{3}{ }^{-}$in complex 1 and $\mathrm{CH}_{3} \mathrm{COO}^{-}$in complex 2 lose electrons to present negative charges of $-0.706 e$ and $-0.524 e$, respectively. The triazole rings in the complexes with negative charges of $-0.398 e,-0.290 e$, respectively, also lose electrons since the triazole rings in $\mathbf{L}$ have negative charges of $-0.356 e$. So it can be inferred that the electrons transfer from the triazole rings and anions into the metal cations. The result is responsible for the reduction of polarity of the atoms in the complexes and consequently helpful to enhance the bioactivities, because the reduction of polarity of the atoms makes contribution to the enhanced penetration of the metal complexes into the lipid membranes. ${ }^{37-39}$

2.4.4 Fukui function. Fukui functions are widely used local density functional descriptors to model chemical reactivity and selectivity. ${ }^{40}$ Based on such a concept, the Fukui functions can help to identify the nucleophilic/electrophilic nature of a specific site within a molecule, which can also predict the active sites of the compound interacting with biological species. ${ }^{41}$ Fukui functions for selected atomic sites in complexes 1 and 2 have also been listed in Table $5 . f_{\mathrm{k}}^{+}, f_{\mathrm{k}}{ }^{-}$and $f_{\mathrm{k}}{ }^{0}$ signs show nucleophilic, electrophilic and radical attack, respectively.

Table 5 Mulliken atomic charges and Fukui functions for atoms of 1 and 2

\begin{tabular}{llllll}
\hline & Atoms & Atomic charges $(e)$ & $f_{k}{ }^{+}$ & $f_{k}{ }^{-}$ & $f_{k}{ }^{0}$ \\
\hline 1 & Cu & 0.613 & 0.073 & 0.077 & 0.075 \\
& N1 & -0.415 & 0.019 & 0.019 & 0.019 \\
& C2 & 0.156 & 0.001 & 0.001 & 0.001 \\
& N3 & -0.206 & 0.011 & 0.011 & 0.011 \\
& N2 & -0.140 & 0.003 & 0.002 & 0.003 \\
& C1 & 0.210 & 0.006 & 0.006 & 0.006 \\
& O5 & -0.386 & 0.085 & 0.086 & 0.085 \\
& O6 & -0.472 & 0.061 & 0.062 & 0.061 \\
& O7 & -0.433 & 0.074 & 0.075 & 0.075 \\
& N7 & 0.585 & 0.021 & 0.021 & 0.021 \\
2 & 0.618 & 0.098 & 0.192 & 0.145 \\
& N1 & -0.389 & 0.020 & 0.011 & 0.015 \\
& C2 & 0.192 & 0.012 & 0.013 & 0.012 \\
& N3 & -0.389 & 0.039 & 0.039 & 0.039 \\
& N2 & -0.138 & 0.018 & 0.020 & 0.019 \\
& C1 & 0.251 & 0.012 & 0.012 & 0.012 \\
& O1 & -0.539 & 0.042 & 0.035 & 0.038 \\
& O2 & -0.540 & 0.075 & 0.056 & 0.038 \\
& C15 & 0.500 & 0.024 & 0.022 & 0.023 \\
& C16 & -0.346 & 0.027 & 0.022 & 0.024 \\
L & N1 & -0.330 & 0.036 & 0.035 & 0.035 \\
& C2 & 0.139 & 0.025 & 0.030 & 0.028 \\
& N2 & -0.141 & 0.003 & 0.006 & 0.001 \\
& N3 & -0.203 & 0.003 & 0.007 & 0.005 \\
& C1 & 0.179 & 0.007 & 0.022 & 0.015 \\
& & & & &
\end{tabular}

The maximum values of the local electrophilic reactivity descriptors, electrophilic reactivity descriptors and radical attack reactivity descriptors at $\mathrm{Cu}$ cations, the anions and $\mathrm{N}$ atoms from triazole rings of complexes $\mathbf{1}$ and $\mathbf{2}$ indicate that these sites are more reactive.

According to the analysis above, it can be observed that the results of HOMO-LUMO, Mulliken atomic charge calculations and Fukui analysis keep consistent, which indicate that the metal cations, coordinated anions and triazole rings may be the active sites of the complexes. However, previous bioactivity results show that the antifungal activities have poor correlation with the coordinated anions, ${ }^{11,27}$ thus the copper cation and the triazole rings originating from the ligand should be the main active sites inhibiting the growth of fungi. However, it is well known that only the triazole ring is the active site of the ligand $\mathbf{L}$, which is also responsible for a rapid selection of resistance strains of $\mathbf{L}$. Thus we can infer that the increased active site of $\mathrm{Cu}$ cations and the synergic interactions between the $\mathrm{Cu}$ cation and $\mathbf{L}$ should be two factors for the increased bioactivities of the complexes.

Triadimenol belongs to the ergosterol biosynthesis inhibitors, which can impair the pathogenic ability of plant fungi by destroying the structure of the cell membrane. As a result of Mulliken atomic charge calculations, the polarity of the atoms in the complexes is reduced, which is helpful for the enhanced penetration of the metal complexes into the lipid membranes and consequently enhance the bioactivities.

Therefore, the added active site of copper cation, the synergetic interactions between the copper cation and $\mathbf{L}$, as well as the enhanced penetration of the metal complexes into the lipid membranes should be three main reasons for the enhanced antifungal activities after complexation.

\section{Experimental section}

\subsection{Materials and general methods}

Triadimenol was purchased from commercial source and repeatedly recrystallized by isopropyl alcohol solvent. All other reagents were of reagent grade and used as received. Elemental analysis was performed on a Vario EL III elemental analyzer. IR spectrum was carried out on EQUINX 55 with KBr presser bit. Xray diffraction data were collected on a Bruker SMART APEX CCD diffractometer. UV-Vis absorption spectra of the complexes in methanol solution are acquired on Shimadzu UV-78 spectrophotometer. The EPR experiments on $\mathrm{Cu}^{2+}\left({ }^{2} \mathrm{D}_{5 / 2}\right)$ complexes have been performed at room temperature. The field-derivative EPR spectra have been registered by a conventional X-band $(\nu=9.77 \mathrm{GHz})$ Bruker EMX model spectrometer employing. Magnetization and variable-temperature (1.7-300 K) magnetic susceptibility measurements were carried out with a Quantum Design MPMS-XL-7. Experimental susceptibilities were corrected for diamagnetism, temperature-independent paramagnetism.

\subsection{Synthesis of $\left[\mathrm{CuL}_{4}\left(\mathrm{H}_{2} \mathrm{O}\right)_{2}\right] \cdot 2 \mathrm{NO}_{3} \cdot 2 \mathrm{CH}_{3} \mathrm{OH} 1$ and $\left[\mathrm{CuL}_{2}\left(\mathrm{CH}_{3} \mathrm{COO}\right)_{2}\right] 2$}

A solution of copper nitrate trihydrate $(0.2416 \mathrm{~g}, 1 \mathrm{mmol})$ or copper acetate monohydrate $(0.1997 \mathrm{~g}, 1 \mathrm{mmol})$ in methanol 
(5 mL) was added drop wise to a solution of triadimenol $(0.5915 \mathrm{~g}, 2 \mathrm{mmol})$ in methanol $(10 \mathrm{~mL})$. The resulting mixture was refluxed for $4 \mathrm{~h}$ to give a clear solution, and then cooled to room temperature. Upon slow evaporation, blue crystals were obtained at room temperature.

1: blue crystals, yield: $52 \% . \mathrm{C}_{58} \mathrm{H}_{84} \mathrm{Cl}_{4} \mathrm{CuN}_{14} \mathrm{O}_{18}$ : anal. calc. $\mathrm{C}$ 47.37, H 5.76, N 13.33; found: C 47.94, H 5.81, N 13.12. IR (KBr, $\left.\sigma / \mathrm{cm}^{-1}\right): 3362(\mathrm{~m}), 3133(\mathrm{~m}), 2963(\mathrm{~s}), 2867(\mathrm{w}), 1588(\mathrm{~s}), 1534$ (s), $1467(\mathrm{~s}), 1220(\mathrm{~m}), 1077(\mathrm{~m}), 1002(\mathrm{~m}), 819(\mathrm{~m}), 730(\mathrm{~m})$, $668(\mathrm{~m})$.

2: blue crystals, yield: $68 \% . \mathrm{C}_{32} \mathrm{H}_{42} \mathrm{Cl}_{2} \mathrm{CuN}_{6} \mathrm{O}_{8}$ : anal. calc. $\mathrm{C}$ 49.71, H 5.48, N 10.87; found: C 49.16, H 5.68, N 11.03. IR (KBr, $\left.\sigma / \mathrm{cm}^{-1}\right): 3340(\mathrm{~m}), 3137(\mathrm{~m}), 2963(\mathrm{~m}), 2867(\mathrm{w}), 1578(\mathrm{~s}), 1491$ (s), 1403 (s), 1220 (m), 1020 (m), 811 (m), 752 (m), 659 (m).

\subsection{X-ray crystallography}

Single-crystal X-ray diffraction (XRD) measurements of $\mathbf{1}$ and $\mathbf{2}$ were carried out on a Bruker SMART APEX CCD diffractometer equipped with a graphite monochromator using Mo K $\alpha$ radiation $(0.71073 \AA)$ at $296(2) \mathrm{K}$ in the $F-\omega$ scan mode. Unit cell dimensions were obtained with least-squares refinements and semi-empirical absorption corrections were applied using the SADABS program. ${ }^{42}$ The structures were solved by direct methods and refined by full-matrix least squares techniques based on $F^{2}$ with the SHELXTL program. ${ }^{43}$ All non-hydrogen atoms were obtained from the difference Fourier map and refined with atomic anisotropic thermal parameters. The hydrogen atoms were added according to the theoretical models. Crystallographic data of complexes 1 and 2 have been deposited at the Cambridge Crystallographic Data Center with CCDC 1414257 and 1055002.

\subsection{Antifungal assay}

Four important phytopathogens (Elsinoe ampelina, Glomerella cingulata, Physalospora berengeriana and Gibberella saubinetii) were provided by Shaanxi Microbiology Institute, China, and selected for antifungal activity studies. The antifungal activities were carried out by the mycelial growth rate method. ${ }^{11,32}$ The ligand $\mathbf{L}$ and the title complexes were diluted by starch and ground into dust, then added to potato dextrose agar (PDA) medium, respectively, to obtain a range of concentrations $(1,2$, 4 and $\left.8 \mathrm{mg} \mathrm{L}^{-1}\right)$ before pouring into the Petri dishes $(7.5 \mathrm{~cm}$ in diameter). The antifungal activities of the metal salts $\mathrm{Cu}\left(\mathrm{NO}_{3}\right)_{2} \cdot 3 \mathrm{H}_{2} \mathrm{O}, \mathrm{Cu}\left(\mathrm{CH}_{3} \mathrm{COO}\right)_{2} \cdot \mathrm{H}_{2} \mathrm{O}$ were also investigated in the range of concentrations of 10, 20, 40 and $80 \mu \mathrm{mol} \mathrm{L}^{-1}$. Each concentration was tested in triplicate. Parallel controls were maintained with starch mixed with PDA medium. The diameter of fungal colonies on PDA plates was measured after $72 \mathrm{~h}$. Percentage inhibition of mycelial growth was calculated using the formula (1). Because the synthesized complexes can be regarded as molecular-level mixtures of $\mathbf{L}$ and inorganic salts, synergy ratios (SR) were calculated to investigate the extent of the interactions between $\mathbf{L}$ and inorganic salts according to Wadley approach ${ }^{22}$ using the formulas (2) and (3).
$\%$ inhibition $=$

(colony diameter of control) - (colony diameter of compound) (colony diameter of control)

$$
\begin{gathered}
\mathrm{EC}_{50}(\text { expected })=(a+b) /\left[\left(a / \mathrm{EC}_{50 \mathrm{~A}}\right)+\left(b / \mathrm{EC}_{50 \mathrm{~B}}\right)\right] \\
\left.\mathrm{SR}=\mathrm{EC}_{50}(\text { expected }) / \mathrm{EC}_{50} \text { (observed }\right)
\end{gathered}
$$

where A, B are two antifungal components; $a, b$ indicate the ratios of $\mathrm{A}$ and $\mathrm{B}$ to the complex, respectively: If $\mathrm{SR} \leq 0.5$, the level of interaction of single componets in complex is antagonistic; if $0.5>\mathrm{SR}<1.5$, the level is additive; if $\mathrm{SR} \geq 1.5$, the level is synergistic.

\subsection{Computational method}

The entire calculations are carried out with the $\mathrm{DMol}^{3}$ software, ${ }^{\mathbf{4 4}}$ which is based on the density functional theory. Symmetry operations were applied for all structures. The generalized gradient approximation (GGA) of Perdew, Burke, and Ernzerhof (PBE) exchange-correlation functional ${ }^{45}$ is used. Double numerical basis sets including polarization functions (DNP $)^{\mathbf{4 6 , 4 7}}$ are performed to describe the valence orbitals of all the atoms in our calculations. To describe the cores, all-electron relativistic calculations are used.

\section{Conclusions}

Two $\mathrm{Cu}(\mathrm{II})$ complexes, $\left[\mathrm{CuL}_{4}\left(\mathrm{H}_{2} \mathrm{O}\right)_{2}\right] \cdot 2 \mathrm{NO}_{3} \cdot 2 \mathrm{CH}_{3} \mathrm{OH}$ (1) and $\left[\mathrm{CuL}_{2}\left(\mathrm{CH}_{3} \mathrm{COO}\right)_{2}\right](2)$, were synthesized using the commercial fungicide triadimenol as ligand. The $\mathrm{Cu}$ atoms in both the complexes adopt the same coordination geometry, but have different coordination environment due to the different coordination sphere the counter anions. Both the $\mathrm{Cu}$ (II) complexes show more active to inhibit the four selected fungi than the ligand triadimenol, which indicates the potential applications of these complexes in the fields as antifungal agents. Furthermore, complex 1 has stronger antifungal activities than complex 2 since the synergy levels were better for the ratio $1: 4$ of copper cation and triadimenol than that for the ratio $1: 2$. The experimental investigation of the synergistic interactions between $\mathrm{Cu}^{2+}$ and triadimenol, in conjunction with the theoretical investigations of the electronic structures of the complexes reveal that the new active site of $\mathrm{Cu}$ cation, the synergic interactions between the $\mathrm{Cu}$ cation and triadimenol, as well as the greater penetration through the cell membrane of microorganisms all contribute to the enhanced biocidal properties.

\section{Conflicts of interest}

There are no conflicts to declare.

\section{Acknowledgements}

This work is funded by the Provincial Natural Science Foundation of Shaanxi, China (Grant No. 2016JZ003). 


\section{Notes and references}

1 R. R. Dalvi and C. D. Howell, Bull. Environ. Contam. Toxicol., 1977, 17, 225-232.

2 I. S. Kim, L. A.Beaudette, J. H. Shim, J. T. Trevors and T. S. Yong, Plant Soil, 2002, 239, 321-331.

3 J. A. Zarn, B. J. Brschweiller and J. R. Schlatter, Environ. Health Perspect., 2003, 111, 255-261.

4 S. Pille and M. Koppel, Agric. Food Sci., 2010, 19, 34-42.

5 R. D. Horsley, J. D. Pederson, P. B. Schwarz, K. McKay, M. R. Hochhalter and M. P. McMullen, Agron. J., 2006, 98, 194-197.

6 L. Lucini and G. P. Molinari, Pest Manage. Sci., 2009, 65, 440443.

7 Y. H. Wang, D. Y. Yu, P. Xu, B. Y. Guo, Y. F. Zhang, J. Z. Li and H. L. Wang, Ecotoxicol. Environ. Saf., 2014, 107, 276-283.

8 M. Kamiya and K. Kameyama, Chemosphere, 2001, 45, 231235.

9 E. Morillo, T. Undabeytia, C. Maqueda and A. Rams, Chemosphere, 2002, 47, 747-752.

10 P. Z. Zhang, Q. Y. Fu, R. X. Chi, C. X. Yang and J. G. Xu, J. Zhejiang Univ. Sci. Technol., 2003, 15, 142-145.

11 X. Chen and C. L. Yang, J. Agric. Food Chem., 2009, 57, 24412446.

12 L. G. Yarullina, R. I. Kasimova, B. R. Kuluev, O. B. Surina, L. M. Yarullina and R. I. Ibragimov, Agric. Sci., 2014, 5, 906-912.

13 M. Miazzi and H. R. Hajjeh, J. Plant Pathol., 2011, 93, 729735.

14 J. C. Kapteyn, J. B. Pillmoor and M. A. De Waard, J. Pestic. Sci., 1992, 34, 37-43.

15 S. Hippe and U. Giesen, Ann. Appl. Biol., 2010, 112, 79-90.

16 T. L. Peever and M. G. Milgroom, Phytopathology, 1992, 82, 821-828.

17 R. A. Wyand and J. K. Brown, Fungal Genet. Biol., 2005, 42, 726-735.

18 P. Z. Zhang, J. Wu, Y. Q. Gong, X. R. Hu and J. M. Gu, Chin. J. Inorg. Chem., 2003, 19, 909-912.

19 K. Qian, Y. B. Jin and Y. X. Li, Chin. J. Inorg. Chem., 2006, 22, 1671-1674.

20 J. Li, T. Xi, B. Yan, M. Y. Yang, H. X. Ma and J. R. Song, Chin. J. Struct. Chem., 2015, 34, 1825-1829.

21 R. Y. Wang, C. C. Shi, Q. Shi, Y. C. Gao and Q. Z. Shi, Chin. J. Inorg. Chem., 2000, 16, 3321-3327.

22 A. B. P. Lever, Inorganic Electronic Spectroscopy, Elsevier, Amsterdam, 2nd edn, 1984.

23 A. P. S. Pannu, P. Kapoor, G. Hundal, R. Kapoor, M. R. Martin, J. B. Rayond and S. H. Maninder, Polyhedron, 2011, 30, 1691-1702.
24 S. Chandra and G. K. Lokesh, Spectrochim. Acta, Part A, 2004, 60, 1751-1761.

25 S. R. Choudhury, C. Y. Chen, S. Seth, T. Kar, H. M. Lee, E. Colacio and S. Mukhopadhyay, J. Coord. Chem., 2009, 62, 540-551.

26 K. R. Gruenwald, A. M. Kirillov, M. Haukka, J. Sanchiz and A. J. L. Pombeiro, Dalton Trans., 2009, 12, 2109-2120.

27 J. Li, T. Xi, B. Yan, M. Y. Yang, J. R. Song and H. X. Ma, New J. Chem., 2015, 39, 6997-7003.

28 F. M. Wadley, Experimental statistics in entomology, Graduate School Press, Washington State University, Pullman, 1976.

29 H. Saral, Ö. Özdamar, İ. Uçar, Y. Bekdemir and M. Aygün, J. Mol. Struct., 2016, 1103, 9-19.

30 J. X. Mu, Z. W. Zhai, M. Y. Yang, Z. H. Sun, H. K. Wu and X. H. Liu, Crystals, 2016, 6, 4.

31 M. Larif, A. Adad, R. Hmammouchi, A. I. Taghki, A. Soulaymani, A. Eimidaoui, M. Bouachrine and T. Lakhlifi, Arabian J. Chem., 2017, 10, 946-955.

32 J. X. Mu, Y. X. Shi, M. Y. Yan, Z. H. Sun and X. H. Liu, Molecules, 2016, 21, 68.

33 W. Boufas, N. Dupont, M. Berredjem, K. Berrezag, I. Becheker, H. Berredjem and N. E. Aouf, J. Mol. Struct., 2014, 1074, 180-185.

34 P. Govindasamy, S. Gunasekaran and S. Srinivasan, Spectrochim. Acta, Part A, 2014, 130, 329-336.

35 K. C. Zheng, J. P. Wang, W. L. Peng, Y. Shen and F. C. Yun, Inorg. Chim. Acta, 2002, 328, 247-253.

36 V. Balachandran, S. Rajeswari and S. Lalitha, J. Mol. Struct., 2012, 1007, 63-73.

37 G. B. Bagihalli, P. G. Avaji, S. A. Patil and P. S. Badami, Eur. J. Med. Chem., 2008, 43, 2639-2649.

38 C. R. A. María, C. L. S. Estefania, S. Jesús, P. Pelagatti and F. Zani, J. Inorg. Biochem., 2005, 99, 2231-2239.

39 J. Li, Y. Zhang, M. Y. Yang and H. X. Ma, RSC Adv., 2017, 7, 33364-33372.

40 K. Fukui, T. Yonezzawa and H. Shingui, J. Chem. Phys., 1952, 20, 722-725.

41 C. J. Brala, I. Fabijanić, A. K. Marković and V. Pilepić, Comput. Theor. Chem., 2014, 1049, 1-6.

42 G. M. Sheldrick, SADABS, University of Göttingen, Germany, 2000.

43 G. M. Sheldrick, Acta Crystallogr., Sect. A: Found. Crystallogr., 2008, 64, 112-122.

44 B. Delley, Phys. Rev. B, 2002, 65, 85403-85409.

45 J. P. Perdew, K. Burke and M. Ernzerhof, Phys. Rev. Lett., 1996, 77, 3865.

46 B. Delley, J. Phys. Chem., 1996, 100, 6107-6110.

47 W. J. Hehre, L. Radom, P. V. R. Schlyer and J. A. Pople, $A b$ Initio Molecular Orbital Theory, Wiley, New York, 1986. 